\title{
Serum p55 and p75 tumour necrosis factor receptors as markers of disease activity in juvenile chronic arthritis
}

Marco Gattorno, Paolo Picco, Antonella Buoncompagni, Franca Stalla, Paola Facchetti, Maria Pia Sormani, Vito Pistoia

\begin{abstract}
Objective-To determine the expression of tumour necrosis factor $\alpha$ (TNF $\alpha)$ and its soluble receptors (p55 and p75) in the sera and synovial fluid of patients with juvenile chronic arthritis (JCA), and their correlation with disease activity parameters.

Methods-Ninety eight sera from 45 patients with JCA (14 systemic, 12 polyarticular, 19 pauciarticular), 20 sera from age matched healthy controls, and five synovial fluids from five antinuclear antibody (ANA) positive pauciarticular JCA patients were tested for the presence of TNF $\alpha$, soluble TNF receptors p55 and p75 (sTNFRp55, sTNFRp75), and interleukin-6 (IL-6) by an enzyme amplified sensitivity immunoassay. Physician global estimate of disease activity, weekly fever score and joint score, $C$ reactive protein (CRP), erythrocyte sedimentation rate (ESR), and haemoglobin concentration were evaluated as parameters of disease activity. The expression of p55 and p75 on peripheral mononuclear cells (MNCs) from five patients with systemic JCA and synovial MNCs from five ANA positive patients with pauciarticular JCA was evaluated by flow cytometry.
\end{abstract}

Results-TNF $\alpha$ serum concentrations did not differ significantly between the patients with active JCA and the control group. No correlation was found between TNF $\alpha$ and parameters of disease activity, but both $\mathrm{p} 55$ and 75 showed a significant positive correlation with the physician global estimate of disease activity $(p<0.001)$, ESR $(p<0.001)$, CRP $(p<0.001)$, and serum concentrations of IL-6 $(p<0.001)$. Serum concentrations of haemoglobin correlated inversely with the concentrations of $\mathrm{p} 55$ and p75 (p < 0.001). Synovial lymphocytes selectively expressed the p75 surface receptor.

Conclusions-sTNFRp55 and sTNFRp75 each represent a sensitive marker of disease activity in JCA. Their increased expression in biological fluids may support the hypothesis that TNF $\alpha$ has a role in the pathogenesis of JCA.

(Ann Rheum Dis 1996; 55: 243-247)

There are many in vitro and in vivo studies suggesting that $\mathrm{TNF} \alpha$ can have a key role in the pathogenesis of rheumatoid arthritis (RA). TNF $\alpha$ and interleukin-1 (IL-1) are able to stimulate bone resorption in vitro, to induce the expression of adhesion molecules including intercellular adhesion molecule-1 (ICAM-1), E-selectin, and vascular cell adhesion molecule-1 (VCAM-1) on endothelial cells, and to stimulate synovial cell production of prostaglandin $\mathrm{E}_{2}$ and collagenase. ${ }^{1}$

In the collagen induced arthritis model in DBA/1 mice, treatment with monoclonal $\mathrm{TNF} \alpha$ antibodies reduced joint swelling and cartilage and bone erosion. ${ }^{2}$ A transgenic mouse expressing human $\mathrm{TNF} \alpha$ developed a symmetric polyarthritis characterised by cartilage destruction, bone erosion, and leucocyte infiltration. ${ }^{3}$ Finally, in a recent double blind trial, the administration of $\mathrm{TNF} \alpha$ chimeric monoclonal antibodies has been shown to be effective and safe in the short term treatment of patients with RA. ${ }^{4}$

TNF $\alpha$ has been detected in sera and synovial fluids and at the cartilage-pannus junction in patients with RA. The few studies conducted on the expression of cytokines in the biological fluids of patients with juvenile chronic arthritis (JCA) have shown that, unlike other proinflammatory cytokines (particularly IL-1 and IL-6), TNF $\alpha$ is found in sera and synovial fluids in small amounts. ${ }^{5-9}$

The soluble TNF $\alpha$ receptors p55 and p75 (sTNF $\alpha$ Rp55, sTNF $\alpha$ Rp75) neutralise the biological activity of TNF $\alpha$ in the fluid phase, and their shedding from the cell surface is believed to be related to $\mathrm{TNF} \alpha$ production. ${ }^{10}$ In this study, we have investigated the reciprocal relationship between $\mathrm{TNF} \alpha$ and these soluble receptors in sera from 45 patients with JCA, and evaluated their correlation with parameters of disease activity and with the serum concentrations of interleukin-6 (IL-6), a cytokine that is detected in high concentrations during the acute phase of JCA.

\section{Patients and methods}

The study was approved by the Ethics Committee of our Institute. Forty five patients with JCA (23 men, 22 women) were included in the study. Twenty age matched healthy subjects attending our clinic for a follow up visit after an acute self limiting inflammatory or infectious disease were included as controls after the parents gave their informed consent. Any subject giving a history of inflammatory or infectious disease in the four weeks preceeding 
Clinical characteristics of patients and treatment at the time of the study

\begin{tabular}{|c|c|c|c|}
\hline & $\begin{array}{l}\text { Systemic } \\
(n=14)\end{array}$ & $\begin{array}{l}\text { Polyarticular } \\
(n=12)\end{array}$ & $\begin{array}{l}\text { Pauciarticular } \\
(n=19)\end{array}$ \\
\hline Age (yr) & $4 \cdot 2(1 \cdot 2-12 \cdot 1)$ & $9 \cdot 3(6 \cdot 2-16)$ & $5 \cdot 6(1 \cdot 1-15 \cdot 7)$ \\
\hline Disease duration (yr) & $1 \cdot 4(0 \cdot 2-2 \cdot 6)$ & $3 \cdot 8(0 \cdot 9-6 \cdot 4)$ & $1 \cdot 2(0 \cdot 2-5 \cdot 9)$ \\
\hline $\operatorname{Sex}(M / F)$ & $9 / 5$ & $5 / 7$ & $9 / 10$ \\
\hline \multicolumn{4}{|l|}{ High activity (47 sera) } \\
\hline NSAID (\%) & $15 \cdot 5$ & $61 \cdot 3$ & $54 \cdot 8$ \\
\hline NSAID + GC (\%) & $37 \cdot 5$ & $14 \cdot 3$ & $11 \cdot 7$ \\
\hline NSAID + SMARD (\%) & $24 \cdot 2$ & $35 \cdot 4$ & 9.2 \\
\hline No treatment $(\%)$ & $12 \cdot 8$ & & $25 \cdot 3$ \\
\hline Global estimation score & $3.6(0.5)$ & $3.4(0 \cdot 5)$ & $3.3(0.4)$ \\
\hline Fever score & $2 \cdot 8(0 \cdot 3)$ & ND & ND \\
\hline Joint score & $1 \cdot 4(1 \cdot 2)$ & $2 \cdot 7(0 \cdot 3)$ & $2 \cdot 8(0.7)$ \\
\hline \multicolumn{4}{|l|}{ Low activity ( 51 sera) } \\
\hline NSAID (\%) & $21 \cdot 3$ & $42 \cdot 6$ & $57 \cdot 8$ \\
\hline NSAID + GC (\%) & $49 \cdot 6$ & $28 \cdot 3$ & $20 \cdot 1$ \\
\hline NSAID + SMARD (\%) & $29 \cdot 1$ & $40 \cdot 1$ & 7.5 \\
\hline Off treatment $(\%)$ & & & $16 \cdot 6$ \\
\hline Global estimation score & $1 \cdot 1(0 \cdot 9)$ & $0.86(0.9)$ & $0.7(0.9)$ \\
\hline Fever score & $0.6(0.6)$ & ND & ND \\
\hline Joint score & $0.2(0.2)$ & $0.7(0.5)$ & $0.8(0.4)$ \\
\hline
\end{tabular}

Values are mean (range) or mean (SD), where relevant.

NSAID = Non-steroidal anti-inflammatory drugs; GC = glucocorticoids; SMARD = slow modifying antirheumatic drugs; ND = not done.

the examination was excluded. The mean age of the JCA patients was 6.3 years (range $1-16.3$ years); 14 of them were affected with systemic JCA, 12 with polyarticular JCA, and 19 with pauciarticular JCA according to the European League Against Rheumatism criteria. The pauciarticular group included antinuclear antibody (ANA) positive patients only; neither spondyloarthropathy nor psoriatic arthritis patients were considered. Among the 12 polyarticular JCA patients, four were ANA positive and one was IgM rheumatoid factor positive. The table shows the main characteristics of the patients and the treatment they were receiving at the time of the study. Clinical parameters for disease activity included physician global estimate of disease activity, weekly fever score (systemic JCA), and joint score (systemic, poly-, and pauciarticular JCA). C reactive protein (CRP), haemoglobin concentration, and erythrocyte sedimentation rate (ESR) were evaluated as laboratory parameters of disease activity.

Physician global estimate of disease activity was scored from 0 to $4 .{ }^{11}$ Fever was scored as follows: $0=$ absence of fever flares in the week before examination; $1=1-3$ weekly flares; $2=4-6$ weekly flares; $3=$ daily flares. Joint involvement was graded from 0 to 3 according to the number of painful joints, number of swollen joints, and range of motion: $0=$ absence of any articular involvement; 1 (mild) $=$ fewer than three painful or swollen joints, and a reduction in range of motion of at least a single joint not exceeding $25 \% ; 2$ (moderate) $=4-6$ joints involved or a range of motion between $25 \%$ and $50 \%$ in at least a single joint; 3 (severe) was assigned to patients who displayed inflammatory involvement of seven or more joints or a reduction in range of motion greater than $50 \%$ in at least one joint. Although there are no published data on the usefulness of these clinical parameters, fever and joint scores seemed to correlate well with disease activity in this study.

High disease activity was assessed as physician global estimate of disease activity scored 3 or 4 , fever or joint scores 2 or 3 , and ESR or CRP values increased above the normal range. Low disease activity was defined by physician global estimate of disease activity scores of $0-2$, fever and joint score 0 or 1 , and ESR and CRP values within the normal range.

Ninety eight sera from 45 patients with JCA were tested retrospectively for the presence of TNF $\alpha$, sTNF $\alpha$ Rp55, sTNF $\alpha$ Rp75, and IL-6, at different times during their disease: on three occasions in seven patients, on two occasions in 32 , and on a single occasion in six patients. The corresponding disease activity scores were obtained from the patients' case notes. Aliquots of sera were frozen at $-80^{\circ} \mathrm{C}$ until assayed by enzyme amplified sensitivity immunoassay (EASIA) kits from Medgenix Diagnostic (Fleurus, Belgium), according to the manufacturer's instructions. These tests are based on an oligoclonal system in which several monoclonal antibodies (MAbs) directed against distinct epitopes of TNF $\alpha$, IL-6, sTNF $\alpha$ Rp55, and sTNF $\alpha$ Rp75 are used. The kits for TNF $\alpha$ and IL- 6 assays have been shown to detect both free and soluble receptor bound cytokines. ${ }^{12}$ Briefly, the capture antibodies are attached to the lower and inner surface of the plastic well and standards or samples are added to the well. After incubation, the occasional excess of antigen is removed by washing. The second antibody, horseradish peroxidase labelled antibody, is added, and after incubation and washing, the microtitre plate is washed again to remove unbound enzyme labelled antibodies.

Evaluation of the expression of sTNF $\alpha \mathrm{Rp} 55$ and sTNF $\alpha$ Rp75 on mononuclear cells (MNCs) was performed by flow cytometry using MAbs htr-9 (for p55) and utr-1 (for p75), ${ }^{13}$ kindly provided by Dr Manfred Brockhaus (Hoffman-La Roche, Basel). Staining for both receptors was by indirect immunofluorescence before and after acid stripping of surface $\mathrm{TNF} \alpha$ bound to its receptors. Briefly, cells were resuspended in a 'stripping solution' (sodium chloride $125 \mathrm{mmol} / \mathrm{l}$ and glycine 25 $\mathrm{mmol} / \mathrm{l}$ at $\mathrm{pH} 2.8$ ) for four minutes at $4^{\circ} \mathrm{C}$. Cells were washed in RPMI medium supplemented with $10 \%$ fetal calf serum (both from Seromed Biochrom, Berlin, Germany), stained with $\mathrm{TNF} \alpha \mathrm{R}$ MAbs, and analysed by flow cytometry using a FACScan (BectonDickinson, Mountain View, California, USA) with the gate set on either lymphocytes or monocytes-macrophages. Under the experimental conditions used, fewer than $3 \%$ of CD14 positive cells were consistently detected within the lymphocytes gate. Likewise, $\mathrm{CD} 3$ cells were fewer than $2 \%$ in the gated monocyte-macrophage population.

In a preliminary series of experiments, the mean TNF $\alpha$, sTNF $\alpha$ Rp55, and sTNF $\alpha$ Rp75 concentrations were tested in synovial fluid from five pauciarticular, ANA positive JCA patients.

STATISTICAL ANALYSIS

Quantitative differences between patient groups were assessed by non-parametric statistical analysis using the Mann-Whitney $U$ test. Correlations among sTNF $\alpha$ Rs, parameters of 
disease activity, $\mathrm{TNF} \alpha$, and IL-6 were determined by linear correlation and Spearman's rank test.

\section{Results}

Mean serum concentrations of $\mathrm{TNF} \alpha$ were greater in the JCA patients with high disease activity (31 (SD 44.1) $\mathrm{pg} / \mathrm{ml}$ ) than in those with low disease activity $(24(35) \mathrm{pg} / \mathrm{ml})$ and those in the control group $(15.5(6.9) \mathrm{pg} / \mathrm{ml})$, but there were no statistically significant differences between the three groups. Similarly, there was no significant difference in TNF $\alpha$ serum concentration among the JCA subtypes. There was no correlation between $\mathrm{TNF} \alpha$ and disease activity parameters.

Serum concentrations of IL-6 were significantly increased in patients with active JCA $(60.5(40.9) \mathrm{pg} / \mathrm{ml})$ compared with those with inactive disease $(21.5(7.4) \mathrm{pg} / \mathrm{ml})(\mathrm{p}<0.001)$ or controls $(25(9.5) \mathrm{pg} / \mathrm{ml})(\mathrm{p}<0.001)$, but the concentrations were comparable among the patients with different subtypes of JCA (data not shown).

Concentrations of both sTNF $\alpha$ Rp55 and sTNF $\alpha$ Rp75 correlated positively with phys- ician global estimate of disease activity $(r=0.62$, $\mathrm{p}<0.001 ; r=0.67, \mathrm{p}<0.001$, respectively).

Figure 1 shows the correlations between sTNF $\alpha$ Rp55 and sTNF $\alpha$ Rp75 serum concentrations and parameters of disease activity for all the patients with JCA. A positive correlation was found with both ESR (fig 1) and CRP $(r=0.54, \mathrm{p}<0.001 ; r=0.43, \mathrm{p}<0.001$ for $\mathrm{p} 55$ and p75, respectively), and between each sTNF $\alpha R$ and serum concentrations of IL-6 (fig 1), but haemoglobin concentration was inversely correlated with the serum concentrations of the sTNF $\alpha$ Rs (fig 1).

Figure 2 shows the relationship between the serum concentrations of $s T N F \alpha R p 55$ or $\mathrm{p} 75$ and disease activity in patients with systemic, polyarticular, or pauciarticular JCA. A significant difference was detected for both sTNF $\alpha$ Rp55 and sTNF $\alpha$ Rp75 between patients with the active and inactive systemic and polyarticular disease subtypes, and between the same patients and controls $(p<0.001)$, but a different pattern was observed for pauciarticular JCA: the serum concentrations of sTNF $\alpha$ Rp75 were significantly greater in patients with active disease than in those with inactive disease or in controls $(p<0.001)$,
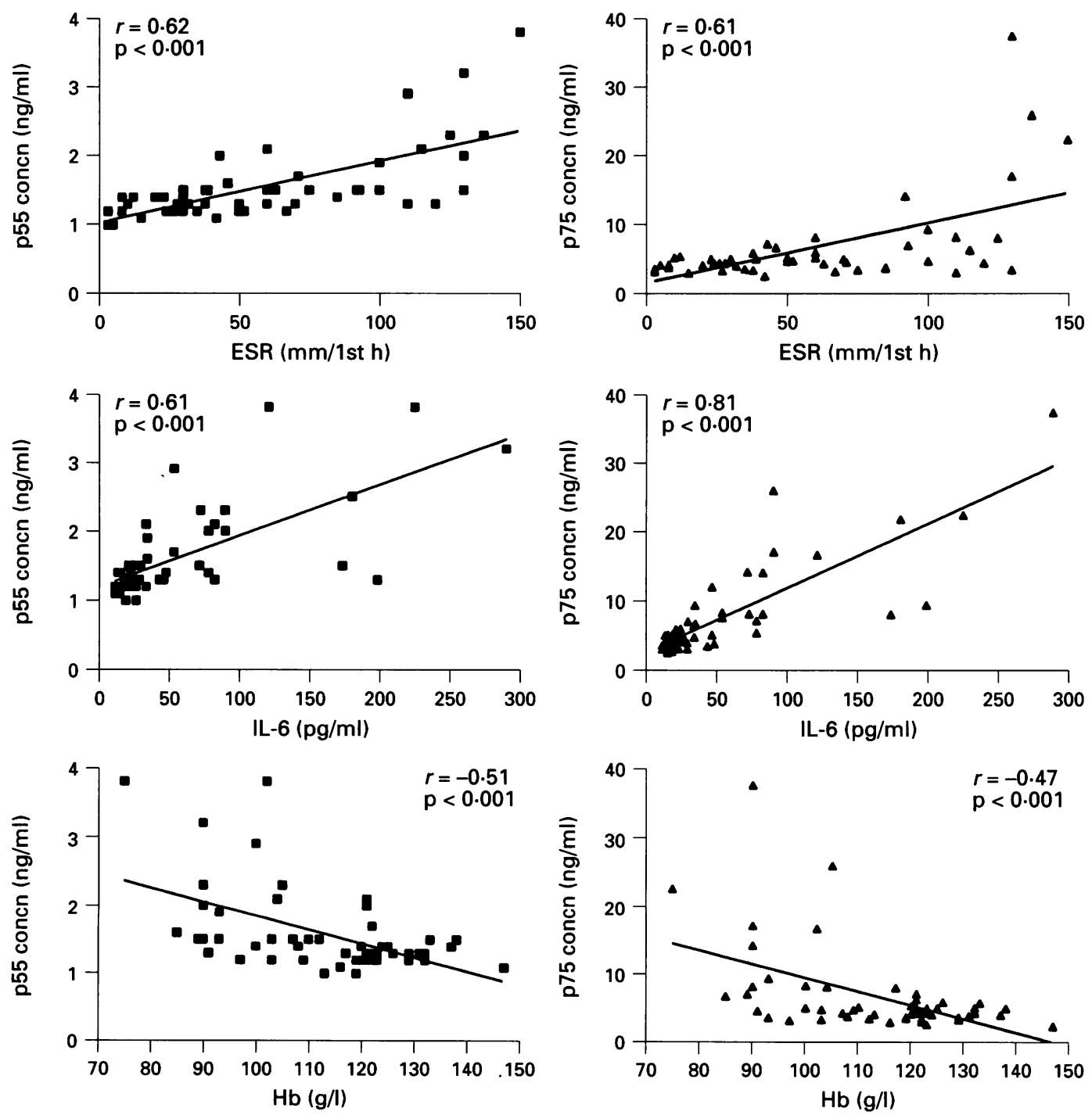

Figure 1 Linear correlations between serum concentrations of soluble tumour necrosis factor $\alpha$ receptors p55 (left) and p75 (right), and erythrocyte sedimentation rate (ESR), interleukin-6 (IL-6) concentration, and haemoglobin (Hb) concentration. 

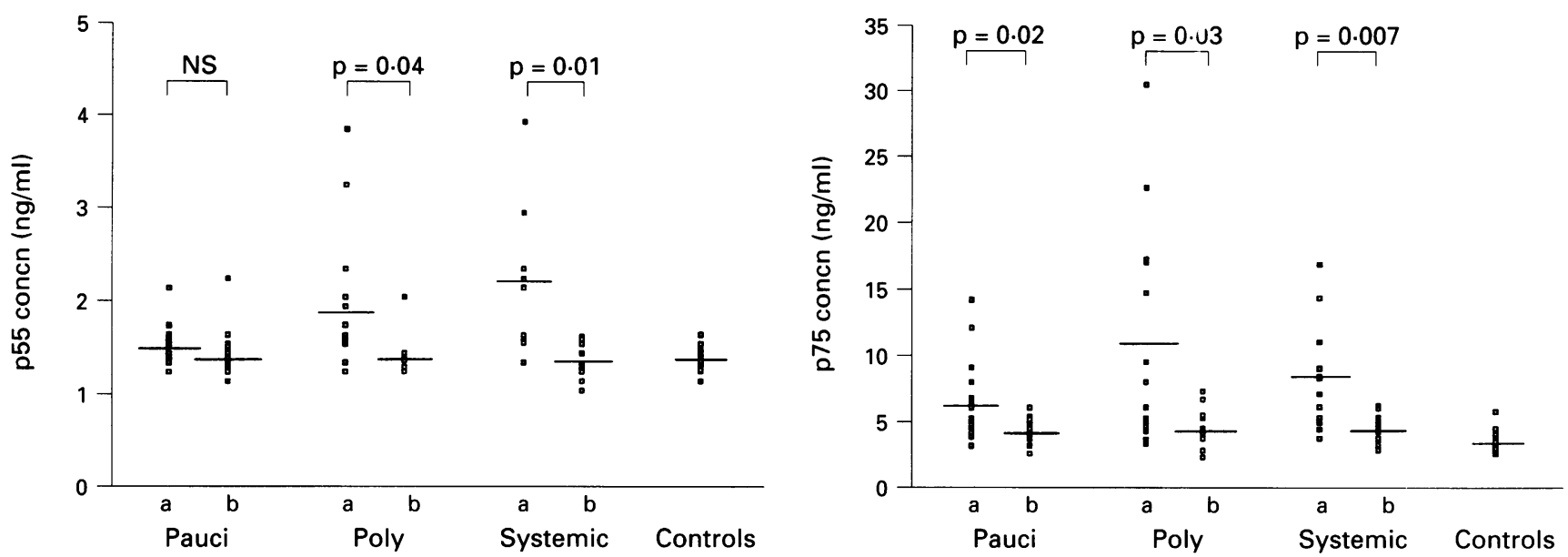

Figure 2 Concentrations of soluble tumour necrosis factor $\alpha$ receptor in patients with active (a) or inactive (b) pauciarticular, polyarticular, or systemic FCA, compared with controls. Horizontal lines represent mean values in each study group.

whereas for sTNF $\alpha$ Rp55 a significant difference was detected only between patients with active disease and controls $(p=0.02)$ (fig 2).

The mean TNF $\alpha$, sTNF $\alpha$ Rp55, and sTNF $\alpha$ Rp75 concentrations in synovial fluid from five pauciarticular, ANA positive JCA patients were $31(15 \cdot 2) \mathrm{pg} / \mathrm{ml}, 10.5(12 \cdot 3) \mathrm{ng} /$ $\mathrm{ml}$, and $19(10.3) \mathrm{ng} / \mathrm{ml}$, respectively. It is of note that, in spite of the variability in individual patients' results, the expression of both sTNF $\alpha$ Rs in synovial fluid was greater than was detected concomitantly in sera, with a trend for concentrations of $s T N F \alpha R p 75$ to be consistently greater than those of the p55 receptors.

Peripheral blood MNCs from five patients with active systemic JCA and synovial MNCs from five patients with pauciarticular JCA were tested by flow cytometry either before or after stripping to remove membrane bound $\mathrm{TNF} \alpha$. No surface sTNF $\alpha$ Rp55 or p75 was detected on the peripheral blood lymphocytes or monocytes of the patients with active systemic JCA, and no surface sTNF $\alpha$ Rp55 was observed on synovial MNC in the pauciarticular patients. In contrast, sTNF $\alpha \mathrm{Rp} 75$ was expressed on the synovial lymphocytes of four of the five patients with pauciarticular JCA, in particular after stripping: $7 \%$ before stripping $v 20 \%$ after stripping; $4 \%$ before $v 13 \%$ after; $8 \%$ before $v$ $14 \%$ after; $11 \%$ before $v 20 \%$ after, respectively. No expression of sTNF $\alpha$ Rp75 was detected on synovial fluid macrophages, either before or after stripping.

\section{Discussion}

In this study, we have investigated the concentrations of TNF $\alpha$, sTNF $\alpha$ Rp55, and sTNF $\alpha$ Rp75 in sera from patients with systemic, pauciarticular, or polyarticular JCA.

Because of the wide interindividual variability, serum concentrations of $\mathrm{TNF} \alpha$ in patients with JCA did not show any significant difference from normal controls. In particular, as reported previously, ${ }^{89}{ }^{14}$ no correlation was found between serum concentrations of TNF $\alpha$ and parameters of disease activity. The implications of these findings are difficult to interpret, particularly as cytokines exert their effects mainly at sites of inflammation. ${ }^{15}$

It is well known that both sTNF $\alpha$ Rs are the shed forms of truncated cell membrane p55 and p75 TNF receptors, produced by proteolytic cleavage. As TNF $\alpha$ itself is one of the best inducers of STNF $\alpha$ R expression, ${ }^{16}$ study of the latter molecules would seem to be a useful indirect indicator of $\mathrm{TNF} \alpha$ production. In our study, the concentrations of both p55 and p75 serum sTNF $\alpha$ Rs were found to be significantly increased, especially during the active phase of JCA. Furthermore, the clinical usefulness of sTNF $\alpha R$ assays was demonstrated by the positive correlation of serum sTNF $\alpha$ Rp 55 and p75 concentrations with the physician global estimate of disease activity, and with with CRP, ESR, and serum concentrations of IL- 6 .

In a recent paper, the serum concentration of $s T N F \alpha R p 55$ was found to be increased in patients with JCA, irrespective of the disease subtype, and the concentrations of the receptor correlated with some indicators of JCA activity. ${ }^{14}$ However, sTNF $\alpha$ Rp75, which we found in the present study to be a sensitive, and sometimes more reliable, marker of JCA activity (pauciarticular subtype) was not studied. In addition, as already reported in $\mathrm{RA}^{17}$ the concentration of sTNF $\alpha$ Rp75 in patient sera was significantly greater than that of sTNF $\alpha$ Rp55.

Our preliminary studies on synovial fluids demonstrated a greater concentration of both TNF $\alpha$ and sTNF $\alpha$ Rs compared with those concomitantly detected in sera, greater concentrations of sTNF $\alpha \mathrm{Rp} 75$ compared with p55, and a selective expression of surface TNF $\alpha$ Rp75 on synovial fluid lymphocytes. All of these findings are in agreement with previous observations in patients with RA. ${ }^{17} 18$

A possible clue to the interpretation of the greater expression of sTNF $\alpha$ Rp75 both in biological fluids and on the lymphocyte surface may come from studies showing that interaction of TNF $\alpha$ with lymphoid or myeloid cells causes a partial but selective shedding of membrane sTNF $\alpha$ Rp75 in the fluid phase. ${ }^{19} 20$ Such a model, however, does not explain why increased concentrations of sTNF $\alpha \operatorname{Rp} 55$ were 
detected in sera from most patients with JCA; it is conceivable that cells other than lymphocytes may be responsible for p55 shedding at the sites of inflammation, as possibly suggested by the expression of surface TNF $\alpha$ Rp55 (in addition to $\mathrm{p} 75$ ) in $\mathrm{RA}$ synovium. ${ }^{21}$

In conclusion, the increased expression of sTNF $\alpha$ Rp55 and p75 in the biological fluids of patients with JCA may represent indirect evidence for the role of TNF $\alpha$ in the pathogenesis of JCA, despite the variable serum concentrations of this cytokine.

We wish to thank Dr M Brockhaus for kindly providing us with his TNF $\alpha$ R monoclonal antibodies, Dr E Franchini for his collaboration, and Drs M Ponzoni and P Montaldo for their helpful suggestions.

1 Brennan F M, Maini R N, Feldmann M. TNF- $\alpha$ : a pivotal role in rheumatoid arthritis? $B r \mathcal{F}$ Rheumatol 1992; 31: 293-8.

2 Williams $R$ O, Feldmann $M$, Maini $R$ N. Anti-tumour necrosis factor ameliorates joint disease in murine 89: $9784-8$.

3 Keffer J, Probert L, Cazlaris $\mathrm{H}$, et al. Transgenic mice expressing human tumor necrosis factor: a predictive genetic model of arthritis. EMBO ₹ 1991; 10: 4025-31.

4 Eliott M J, Maini R M, Feldmann M, et al. Randomised double-blind comparison of chimeric monoclonal antibody to tumour necrosis factor- $\alpha$ (cA2) versus placebo in body to tumour necrosis factor- $\alpha$ (cA2) versus place

5 Prieur M, Kaufman M T, Griscelli C, Dayer J M. Specific interleukin 1 inhibitor in serum and urine of children with systemic JCA. Lancet 1987; 2: 1240-2.

6 De Benedetti F, Massa M, Robbioni P, Burgio G R, Martini A. Correlation of serum interleukin 6 levels with joint involvement and thromocytosis in systemic juvenile rheumatoid arthritis. Arthritis Rheum 1991; 34: 1158-63.

7 Woo P. Cytokines in childhood rheumatic diseases. Arch Dis Child 1993; 69: 547-9.

8 Madson K L, Moore T L, Lawrence J M III, Osborn T G. Cytokine levels in serum and synovial fluid of patients with juvenile rheumatoid arthritis. $\mathcal{f}$ Rheumatol 1994; 21 : 2359-63.

9 Lepore L, Pennesi M, Saletta S, Pertecarari S, Presani G, Prodon M. Study of IL-2, IL-6, TNF- $\alpha, \mathrm{INF} \gamma$ and $\beta$ in the serum and synovial fluid of patients with juvenile chronic arthritis. Clin Exp Rheumatol 1994; 12: 561-6.

10 Fiers W. Tumor necrosis factor. Characterization at the Fiers W. Tumor necrosis factor. Characterization at the
molecular, cellular and in vivo level. FEBS Lett 1991; 285: molecular,

11 Southwood T R, Malleson P N. The clinical history and physical examination. In: Southwood T R, Malleson P N, eds. Arthritis in children and adolescents. Clinical Paediatrics, vol 3. London: Bailliere Tindall, 1993; 637-64.

12 Grau G E. The influence of soluble receptors in cytokine measurement. $\mathcal{F}$ NIH Res 1995; 7: 82.

13 Brockhaus M, Schoenfeld D J, Schlaeger E J, Hunziker W, Lesslauer W, Loetscher H. Identification of two types of tumor necrosis factor receptors on human cell lines by monoclonal antibodies. Proc Natl Acad Sci USA 1990; 87: 3127-31.

14 Mangge H, Kenzian H, Gallistl S, et al. Serum cytokines in juvenile rheumatoid arthritis. Correlation with conventional inflammatory parameters and clinical conventional inflammatory parameters
subtypes. Arthritis Rheum 1995; 38: 211-20.

15 Cope A P, Maini R N. Soluble tumor necrosis factor receptors in arthritis. $\mathcal{F}$ Rheumatol 1995; 22: 382-4.

16 Brennan F M, Cope A P, Katsikis P, Gibbons D L, Maini R N, Feldmann M. Selective immunosuppression of tumor necrosis factor-alpha in rheumatoid arthritis. In: L Adorini, ed. Selective immunosuppression: basic concepts and clincal applications (Chem Immunol), vol 60. Basel: Karger, 1995; 48-60.

17 Cope A P, Aderka D, Doherty M, et al. Increased levels of soluble tumor necrosis factor receptors in the sera and synovial fluid of patients with rheumatic diseases. Arthritis Rheum 1992; 35: 1160-9.

18 Roux-Lombard P, Punzi L, Hasler F, et al. Soluble tumor necrosis factor receptors in human inflammatory synovial necrosis factor receptors in human inflam
fluid. Arthritis Rheum 1993; 36: 485-9.

19 Cope A P, Aderka D, Wallach D, et al. Soluble TNF receptor production by activated $\mathrm{T}$ lymphocytes: differential effects of acute and chronic exposure to TNF. Immunology 1995; 84: 21-30.

20 Higuchi M, Aggarwaal B B. TNF induces internalization of $p 60$ receptor and shedding of the p80 receptor. $f$ Immunol 1994; 152: 3550-8.

21 Brennan F M, Gibbons D L, Mitchell T, Cope A P, Maini R N, Feldmann M. Enhanced expression of tumor necrosis factor receptors mRNA and protein in mononuclear cells isolated from rheumatoid arthritis mononuclear cells isolated from theumatoid at 